\title{
Synthesis and Modification of Carboxylated Multi Wall Nanotubes with Atenolol
}

\author{
Sajjad Sedaghat \\ Department of Chemistry, College of Science, Malard Branch, Islamic Azad University, Malard, Iran \\ Email: sajjadsedaghat@yahoo.com
}

Received 1 May 2014; revised 1 June 2014; accepted 1 July 2014

Copyright (C) 2014 by author and Scientific Research Publishing Inc. This work is licensed under the Creative Commons Attribution International License (CC BY). http://creativecommons.org/licenses/by/4.0/

c) (i) Open Access

\begin{abstract}
In this paper functionalized multiwall carbon nanotubes (FMWCNT) were modified using atenolol as a class of drugs that were used in cardiovascular diseases containing reactable nitrogen, which could attach chemically to functionalized MWCNT. This product was characterized by Fourier transform infrared spectroscopy (FT-IR) and Raman spectroscopy. These spectrums proved the existence of nitrogen atoms of amide due to new functional group. The morphology were also determined by scanning electron microscopy (SEM) and showed that this product was synthesized in the nanometer dimension. Thermal gravimetery (TGA) analysis was also used to evaluate thermal properties.
\end{abstract}

\section{Keywords}

Atenolol, Functinalized Multiwalled Carbon Nanotubes, Modification, Morphology, SEM

\section{Introduction}

In recent years attentions from researchers have been focused on carbon nanotubes (CNTs) due to their size, properties and their electronic, mechanical, optical, and chemical characteristics [1] [2]. These days, new carbon forms such as carbon nanotubes including single wall (SWCNTs) and multiwall (MWCNTs) have generated great interest between researchers in this area. Recently, porous carbon materials as mentioned above and modified nanotubes have been widely used as effective substrates for anchoring some organic compounds and drugs, as a result of their large surface area and high adsorption capacity [3] [4]. The attachment of functional groups or aliphatic carbon chains to the nanotubes can increase the solubility of nanotubes in organic solvents and compatibilize them with polymeric matrices [5]. Atenolol is a selective $\beta_{1}$ receptor antagonist, a drug belonging to the group of beta blockers (sometimes written $\beta$-blockers), a class of drugs used primarily in cardiovascular diseases, introduced in 1976 [6]. Atenolol was also developed as a replacement for propranolol in the treatment of 
hypertension. Unlike propranolol, atenolol does not pass through the blood-brain barrier thus avoiding various central nervous system side effects. Functionalization of MWCNT is an attracting area for attaching molecules containing amine, hydroxyl or amide functional groups to the FMWCNT [7]-[13]. The chemical structure of atenolol is shown Scheme 1.

We know that the presence of different functional groups is the starting point for binding a variety of different chemical molecules onto the nanotube surfaces. The aim of this study is the linkage of atenolol as a drug containing an amine group with FMWCNTs as illustrated in Scheme 2.

\section{Materials and Methods}

\subsection{Materials}

Carboxylated multiwall carbon nanotube (MWNT-COOHs) (95\% purity, 20 - $30 \mathrm{~nm}$ ) was used in this work were purchased from nanocarbon Co. Thionyl chloride $\left(\mathrm{SOCl}_{2}\right)$, THF and DMF from fluka and atenolole were purchased from Aldrich and used as received. Deionized water was also used. Fourier transform infra red (FTIR) spectrum was recorded using KBr tablets on a Perkin Elmer Spectrum-100 FT-IR spectrometer. Raman spectra recorded on Bruker Sentrra-2009 spectrometer. Scanning electron microscope (SEM) was used to study the morphology of the MWNTs. SEM measurement was carried out on the Hitachi 4160 Electron Microscope. And thermal gravimetery (TGA) was also carried out with ASTME-1131 apparatus.

\subsection{Modified FMCNT Synthesis}

$100 \mathrm{mg}$ of MWCNT-COOH were dispersed in $30 \mathrm{~mL}$ of thionyl chloride, then $1 \mathrm{~mL}$ of THF added to the vessel and sonicated for 2 hours at room temperature. Then refluxed in $70^{\circ} \mathrm{C}$ by mixing for 54 hours. The residue thionyl chloride were removed in vacuum by rotary evaporation. Then filtered and washed with THF, the solids were dried in an oven overnight, in this step the surface-bound of carboxylic acid groups were converted into acyl chloride groups. $80 \mathrm{mg}$ of this solid ( MWCNT-COCl) were mixed with $25 \mathrm{~mL}$ of DMF and $200 \mathrm{mg}$ of atenolol were added and ultrasonicated for one hours. The mixture were refluxed in $90^{\circ} \mathrm{C}$ for 72 hours, then cooled to room temperature, filtered and washed with DMF, ethanol and THF, so the residue were dried in an oven for overnight and the solid (modified MWCNT with atenolol) was ready for more evaluations.<smiles>CC(C)NCC(O)COc1ccc(CC(N)=O)cc1</smiles>

Scheme 1. (RS)-2-\{4-[2-Hydroxy-3-(propan-2-ylamino) propoxy] phenyl $\}$ acetamide.

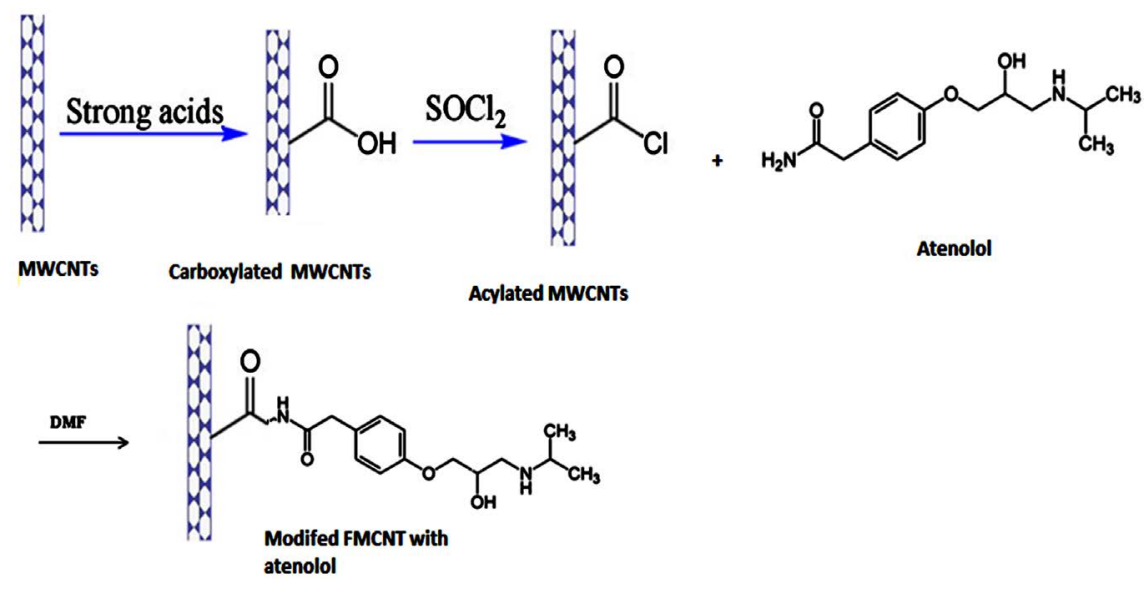

Scheme 2. Strategy for modified FMWCNT synthesis. 


\section{Results and Discussion}

\subsection{FT-IR Characterization}

FT-IR spectra of atenolol is illustrated in Figure 1. Vibration of the N-H stretching for the secondary amine is in $3100-3500 \mathrm{~cm}^{-1}$.

As described in experimental section caroxylated MWCNT was reacted with thionyl chloride to change the acidic functional groups to acyl clorides. The IR spectrums of these two compounds are illustrated in Figure 2 and Figure 3. In Figure 2 the IR spectrum of carboxylated MWCNT is shown, the absorbsion band in the range of $2800-3400 \mathrm{~cm}^{-1}$ is related to the stretching vibration band of $\mathrm{OH}$, in 1713 the absorbsion band is for $\mathrm{C}=\mathrm{O}$ and 1250 for C-O stretching vibration [7].

In Figure 3 the acyl chloride functionalized MWCNTs, shows the change of carbonyl group from 1713 to $1721 \mathrm{~cm}^{-1}$ which is due to the negative inductive effect of chlorine atoms. The appearance of $\mathrm{C}-\mathrm{Cl}$ vibration in $645 \mathrm{~cm}^{-1}$ is another evidence for this product formation.

In Figure 4 the IR spectrum of attached atenolol onto FMWCNT is illustrated. In this spectrum the C-Cl group absorbsion is omitted dealing with the linkage of FMWCNTs to nitrogen of amine group in atenolol Also in this spectrum due to the formation of amide linkage in the final product, the stretching vibration of $\mathrm{C}=\mathrm{O}$ is

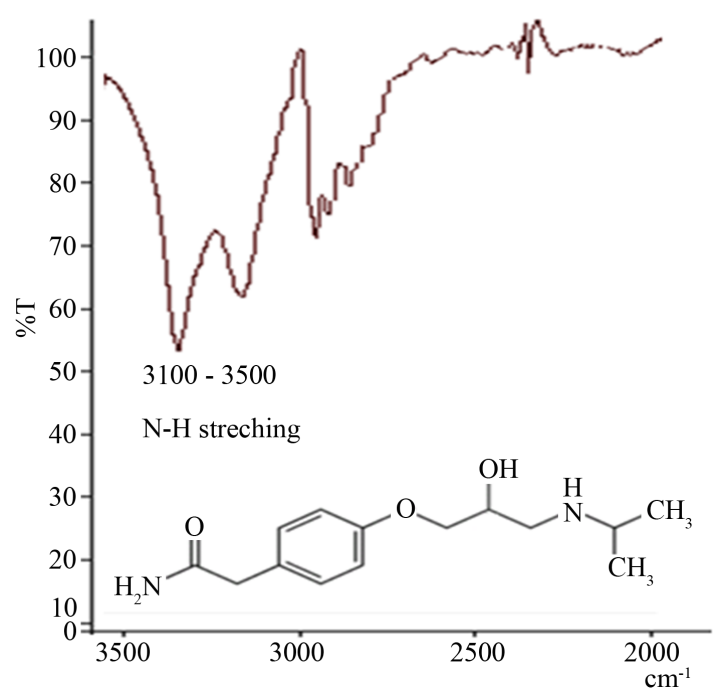

Figure 1. FT-IR spectrum of pure atanolol.

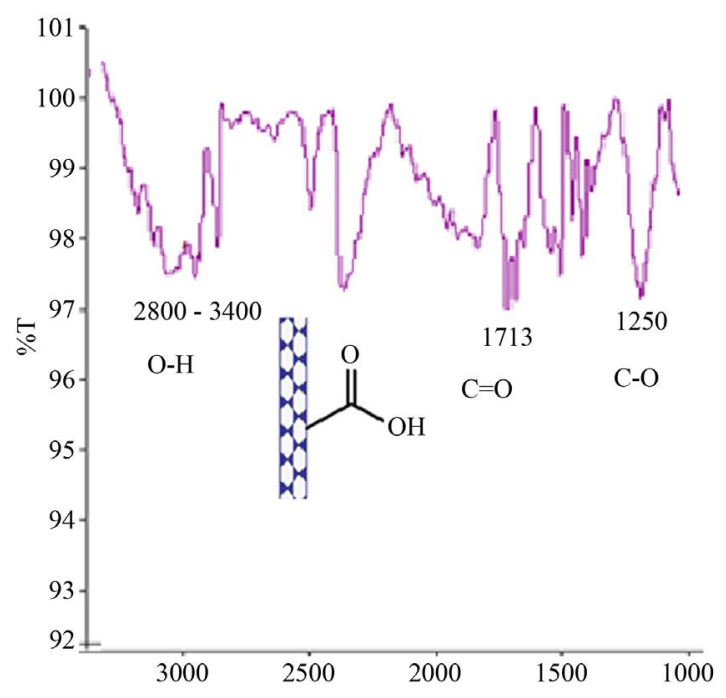

Figure 2. FT-IR spectrum of MWNT-COOH. 


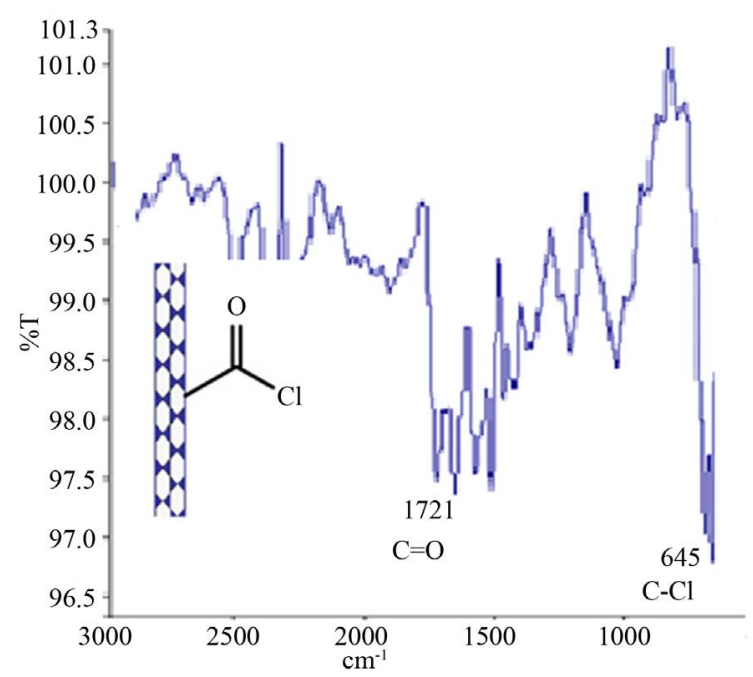

Figure 3. FT-IR spectrum of MWNT-COCl.

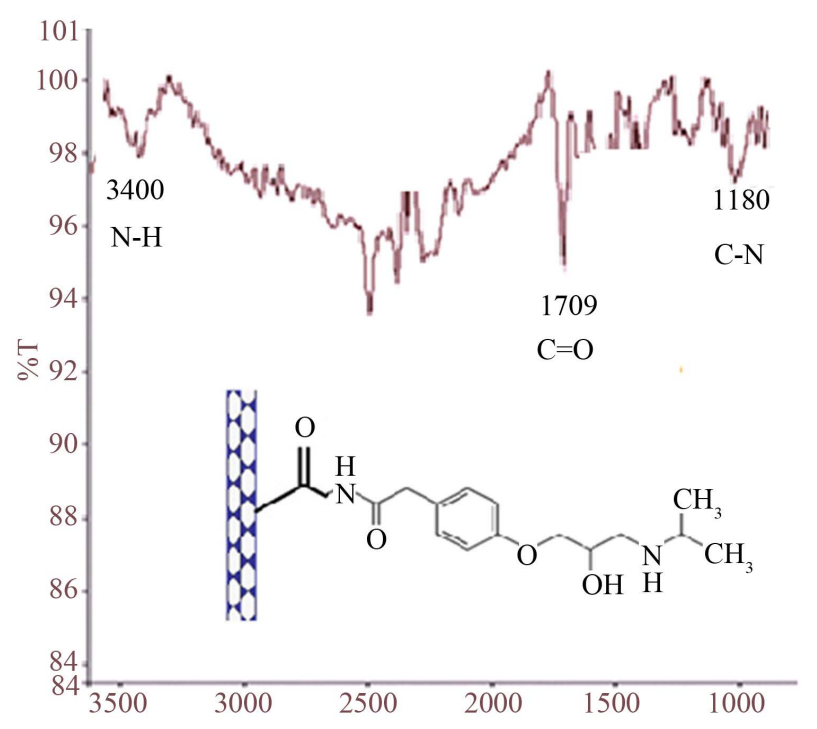

Figure 4. FT-IR spectrum of modified FMCNT with atenolol.

shifted from 1721 to 1709 and the peak at $1180 \mathrm{~cm}^{-1}$ is assigned to the C-N stretching of amide group. The peak at $3400 \mathrm{~cm}^{-1}$ is also for stretching vibration of $\mathrm{N}-\mathrm{H}[7]$.

\subsection{Raman Spectroscopy}

Raman spectra results are powerful tool for characterizing functionalized CNTs. The disorder D band in MWCNTs is observed when the symmetry of hexagonal lattice is disrupted due to, for example, covalent sidewall functionalization. The G mode at around $1600 \mathrm{~cm}^{-1}$ represents the tangential vibration mode of the graphitic structure of the nanotubes. As shown in the spectra from Figure 5, the form of these bands does not modify during functionalization, which means that the global structure of the grapheme sheet does not suffer major damages during functionalization treatments. Still the ratio between the intensities of these two characteristic bands is a quantification of the functional groups introduction, by measuring the $\mathrm{sp}^{3}$ carbon atoms introduced.

Since Raman scattering is strongly sensitive to the electronic structure so the Raman data in Figure 6 show an increase of the ID/IG ratio value as the functionalization by oxidation and then grafting occurs. This tendency is maintained also for the shifting of the D and G bands positions and we can see the ID/IG ratio value is shifted from 0.46 in MWCNT-COOH to 0.41 in MWCNT-COCl and also to 0.44 in the MWCNT-atenolol [9]. 


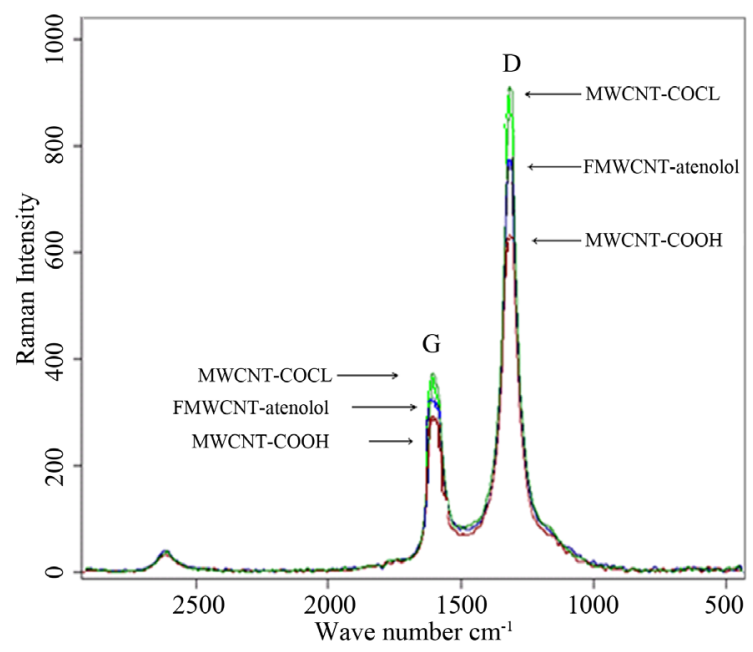

Figure 5. Characteristic bands of raman spectra for MWCNT-COOH; MWCNT-COCl and FMWCNT-atenolol.

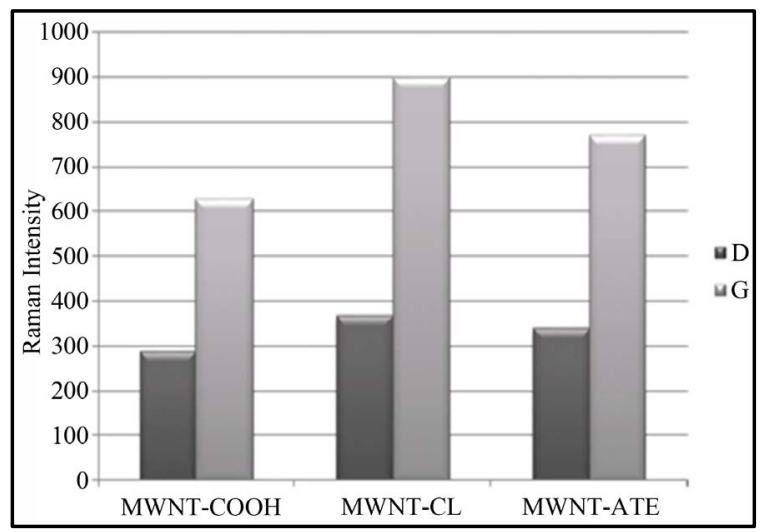

Figure 6. Comparison of ID/IG ratio values in

MWCNT-COOH; MWCNT-COCl and FMWCNT-atenolol.

\subsection{Morphological Characterizations}

The morphology of the compounds were investigated by SEM and are shown in Figure 7. In MWCNT-COOH, it seems that the uniform surfaces of nanotubes are relatively smooth. After the acylation of MWCNT-COOH a tubular layer of halogen attached are presented. Uniform grafting of atenolol onto MWCNTs is clearly presented on the surface of the MWNT (the rough part) and the diameters of the modified MWNTs are slightly increased as compared to that of MWNT-COOH. With modification of the surface of FMWCNT with atenolol and attachment onto the MWCNT by both the covalent bonds and the homogeneous dispersion, the changes in the morphology are clearly shown.

\subsection{Thermo Gravimetric Analysis (TGA)}

Thermo gravimetric analysis (TGA) is a widly used technique for determining the thermal resistance of materials, so in this paper the enhancement of thermal stability for nano compounds are investigated. In Figure 8, we can observe the thermal degradation of MWCNT-OH and nano drug. It is well known that the graphitic structure of carbon nanotubes is stable up to $500^{\circ} \mathrm{C}$, when thermal oxidative processes occur. The oxidation with strong acids of MWCNTs introduces carboxylic groups at the nanotubes surface by creating defects in the hexagonal or pentagonal structures from the graphene sheet or by cutting the semi spherical ends of the CNTs. The degradation process of MWCNT-atanolol starts at $600^{\circ} \mathrm{C}$ normally attributed to the structure of the MWCNT-atenolol (Figure 9). 


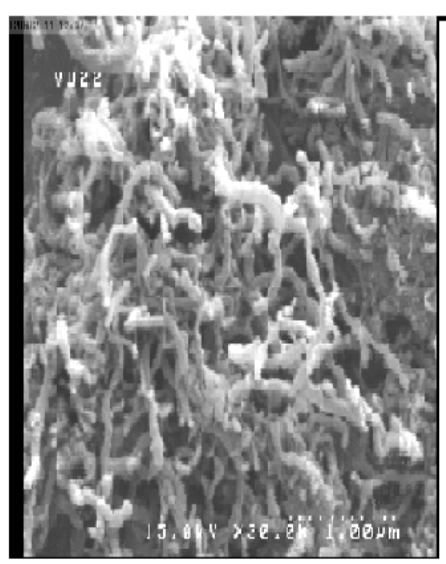

FMWCNT-atenolol

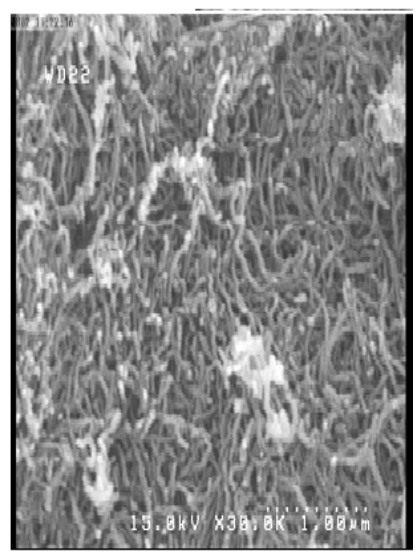

FMWCNT

Figure 7. SEM images of the FMWCNT and FMWCNT-atenolol.

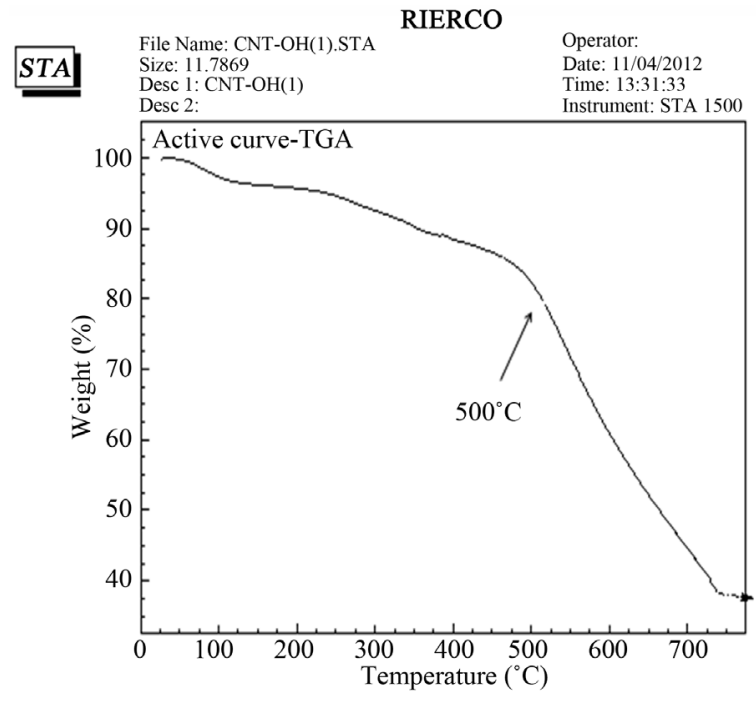

Figure 8. TGA curve of pristine FMWCN.

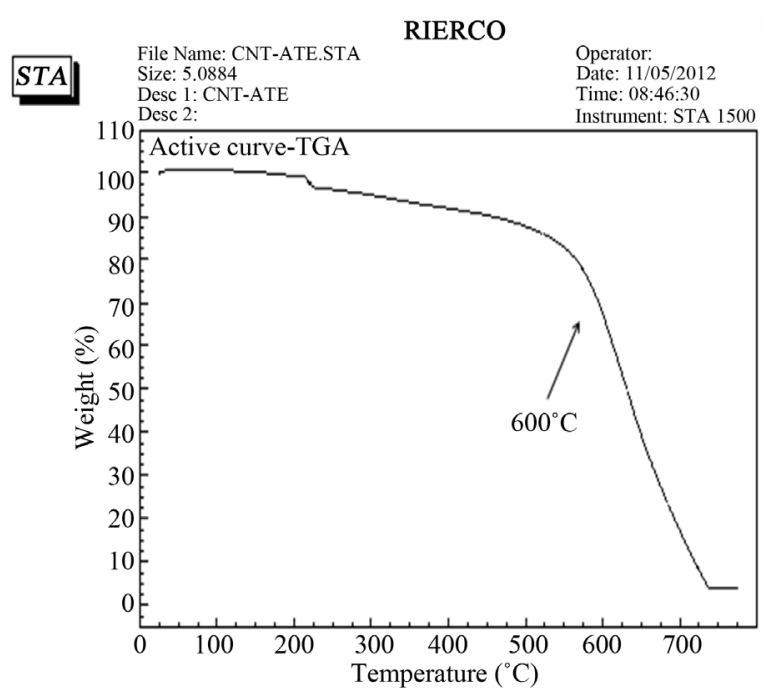

Figure 9. TGA curve of FMWCNT-atenolol. 


\section{Conclusion}

In summary, atenolol was successfully attached to MWCNTs surface by chemical functionalization. The modified functionalized MWCNTs obtained were evaluated, using TGA, FT-IR, SEM and Raman spectroscopy. SEM images showed the formation of the FMWCNT-atenolol and presence of the chemical bonding the matrix. FT-IR results showed the formation of amide in the products and finally the thermo gravimetric analysis (TGA) analysis data has shown the presence of the functional groups attached to the surface of MWCNT and their corresponding degradation with increasing temperature in inert atmosphere.

\section{Acknowledgments}

This work was supported by Islamic Azad University.

\section{References}

[1] Kalita, G., Adhikari, S., Aryal, H.R., Afre, R., Soga, T., Sharon, M. and Umeno, M. (2009) Functionalization of Multi-Walled Carbon Nanotubes (MWCNTs) with Nitrogen Plasma for Photovoltaic Device Application. Current Applied Physics, 351, 346-351. http://dx.doi.org/10.1016/j.cap.2008.03.007

[2] Merkoci, A., Pumera, M., Llopis, X., Perez, B., Valle, M. and Alegret, S. (2005) New Materials for Electrochemical Sensing: Carbon Nanotubes. Trends in Analytical Chemistry, 24, 826-838. http://dx.doi.org/10.1016/j.trac.2005.03.019

[3] Bianco, A., Kostarelos, K. and Prato, M. (2005) Applications of Carbon Nanotubes in Drug Delivery. Current Opinion in Chemical Biology, 9, 674-679. http://dx.doi.org/10.1016/j.cbpa.2005.10.005

[4] Sedaghat, S. and Mehraji, M. (2013) Novel Hybrid of Silver Nono Particles Deposited on to the Different Carbon Substrates and Evaluation of Antibacterial Effects. Journal of Applied Science Engineering Technology, 3, $219-222$.

[5] Dettlaff-Weglikowska, U., Benoit, J.M., Chiu, P.W., Graupner, R., Lebedkin, S. and Roth, S. (2002) Chemical Functionalization of Single Walled Carbon Nanotubes. Current Applied Physics, 2, 497-501. http://dx.doi.org/10.1016/S1567-1739(02)00164-5

[6] Agon, P., Goethals, P., Van Haver, D. and Kaufman, J.M. (1991) Permeability of The Blood-Brain Barrier for Atenolol Studied by Positron Emission Tomography. Journal of Pharmacy and Pharmacology, 43, 597-600. http://dx.doi.org/10.1111/j.2042-7158.1991.tb03545.x

[7] Tahermansouri, H., Chobforosh, D. and Meskinfam, M. (2010) International Journal of Nano Dimension, 1, 153-159158.

[8] Shen, J., Huang, W. and Ye, M. (2007) Thermo-physical properties of epoxy nanocomposites reinforced with aminofunctionalized multi-walled carbon nanotubes. Composite Part A, 38, 1331-1336. http://dx.doi.org/10.1016/j.compositesa.2006.10.012

[9] Mickelson, E.T., Chiang, I.W., Zimmerman, J.L., Boul, P.J., Lozano, J., Liu, J., Smalley, R.E., Hauge, R.H. and Margrave, J.L. (1999) Solvation of Fluorinated Single-Wall Carbon Nanotubes in Alcohol Solvents. The Journal of Physical Chemistry B, 103, 4318-4322. http://dx.doi.org/10.1021/jp9845524

[10] Boul, P.J., Liu, J., Mickelson, E.T., Huffman, C.B., Ericson, L.M., Chiang, I.W., Smith, K.A., Colbert, D.T., Hauge, R. H., Margrave, J.L. and Smalley, R.E. (1999) Reversible Sidewall Functionalization of Buckytubes. Chemical Physics Letters, 310, 367-372. http://dx.doi.org/10.1016/S0009-2614(99)00713-7

[11] Saini, R.K., Chiang, I.W., Peng, H., Smalley, R.E., Billups, W.E., Hauge, R.H. and Margrave, J.L. (2003) Covalent Sidewall Functionalization of Single Wall Carbon Nanotubes. JACS, 125, 3617-3621. http://dx.doi.org/10.1021/ja021167q

[12] Boul, P.J., Turner, K., Li, J., Pulikkathara, M.X., Dwivedi, R.C., Sosa, E.D., Lu, Y., Kuznetsov, O.V., Moloney, P., Wilkins, R., O’Rourke, M.J., Khabashesku, V.N., Arepalli, S. and Yowell, L. (2009) Single Wall Carbon Nanotube Response to Proton Radiation. The Journal of Physical Chemistry C, 113, 14467-14473. http://dx.doi.org/10.1021/jp808553u

[13] Damian, C.-M. and Horia, A.M.P. (2010) Sci. Bull., Series B, 72. 
Scientific Research Publishing (SCIRP) is one of the largest Open Access journal publishers. It is currently publishing more than 200 open access, online, peer-reviewed journals covering a wide range of academic disciplines. SCIRP serves the worldwide academic communities and contributes to the progress and application of science with its publication.

Other selected journals from SCIRP are listed as below. Submit your manuscript to us via either submit@scirp.org or Online Submission Portal.
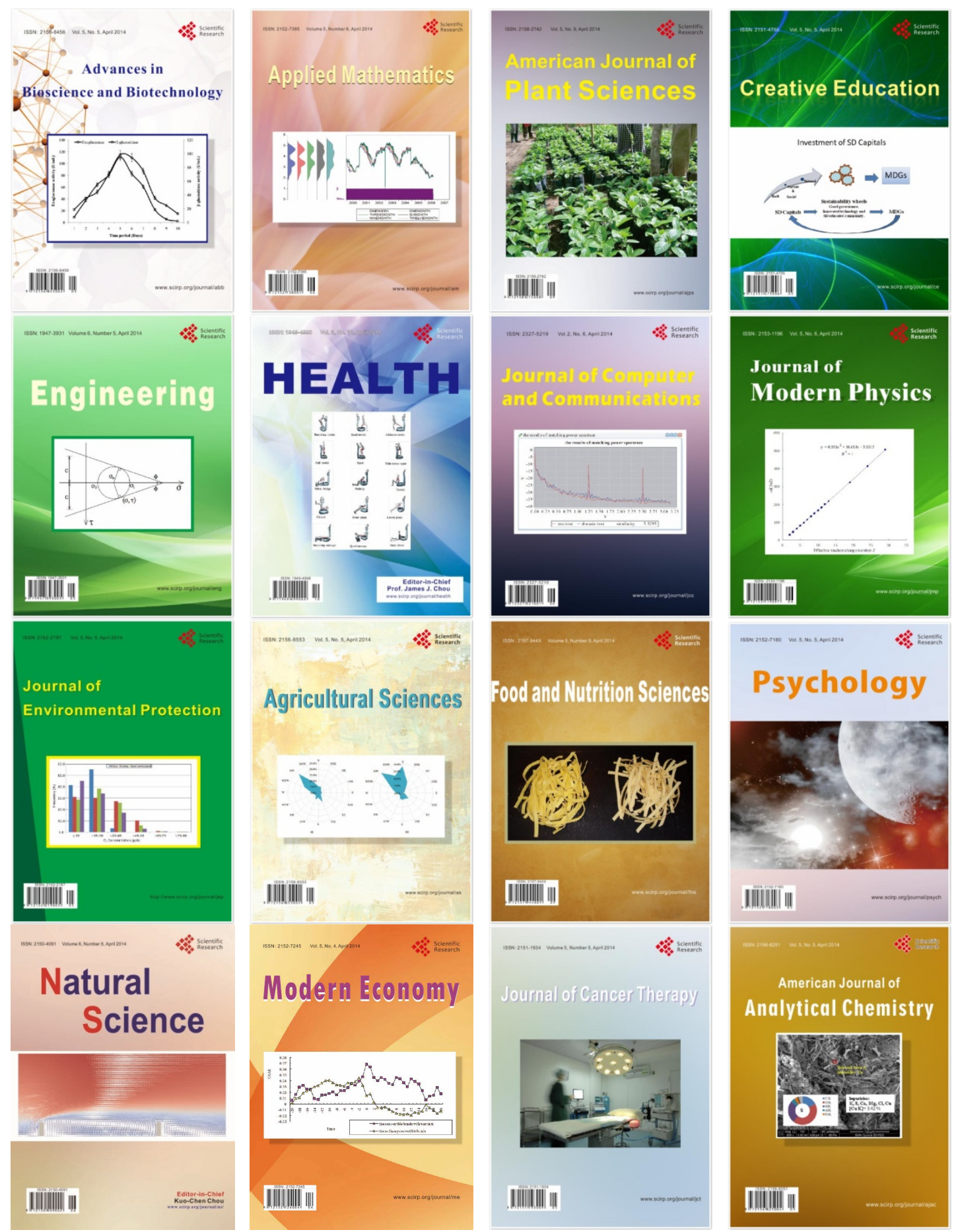